NASA Technical Memorandum 100926

AIAA-88-3105

\title{
Evaluation of the Communications Impact of a Low Power Arcjet Thruster
}

\author{
(AASA-TH-1COS26) EVAILATICN CF IHE \\ CCMUUNICATIOAS IMEACT CF ACK ECREE ABCJET \\ N $88-246 \varepsilon 2$ \\ IEEUSIEE (NASA) 26 E \\ CSCI $21 \mathrm{H}$ \\ $\begin{array}{ll}\text { Unclas } \\ \text { G } 3 / 20 & 0146955\end{array}$
}

Lynnette M. Carney

Lewis Research Center

Cleveland, Ohio

Prepared for the

24th Joint Propulsion Conference

cosponsored by the AIAA, ASME, SAE, and ASEE

Boston, Massachusetts, July 11-13, 1988 
EVALUATION OF THE COMMUNICATIONS IMPACT OF. A LOW POWER ARCJET, THRUSTER

\author{
Lynnette M. Carney \\ National Aeronautics and Space Administration \\ Lewis Research Center \\ Cleveland, $\mathrm{OH} 44135$
}

\begin{abstract}
The interaction of a $1 \mathrm{~kW}$ arcjet thruster plume with a communications signal is evaluated. A two parameter, source flow equation has been used to represent the far flow field distribution of the arcjet plume in a realistic. spacecraft configuration. Modelling the plume as a plasma slab, the interaction of the plume with a $4 \mathrm{GHz}$ communications signal is then evaluated in terms of signal attenuation and phase shift between transmitting and receiving antennae. Except for propagation paths which pass very near the arcjet source, the impacts to transmission appear to be negligible. The dominant signal loss mechanism is refraction of the beam rather than absorption losses due to collisions. However, significant reflection of the signal at the sharp vacuumplasma boundary may also occur for propagation paths which pass near the source.
\end{abstract}

\title{
INTRODUCTION
}

A low power arcjet thruster is currently being developed as a high performance alternative for auxiliary propulsion applications such as north-south stationkeeping on communications satellites (refs. 1 and 2). When operated with storable propellants at power levels between 1.0 and $1.5 \mathrm{~kW}$, the arcjet can provide specific impulse values greater than $400 \mathrm{sec}$, offering potentially large benefits in terms of spacecraft mission life or payload capability. A laboratory arcjet thruster has demonstrated technology readiness in terms of lifetime and performance (ref. 1).

As the arcjet moves closer to being a flight-ready propulsion system, spacecraft integration concerns become of significant interest. Many of the key issues center around the arcjet plume, because of the potential impacts that the plume may have on other spacecraft subsystems. Potential impacts of primary concern include: electromagnetic contamination due to radiated emissions from the arc discharge and plume, induced environment effects on communications signals, thermal loading of sensitive spacecraft surfaces, and momentum losses due to plume impingement. The relative importance of the above concerns depends upon the actual thruster-spacecraft architecture.

In order to accurately assess the arcjet plume impacts, a flow field characterization of the exhaust is required. A partial description of the charged fraction of the arcjet plume has been obtained using electrostatic probes (ref. 3). Measurements $30 \mathrm{~cm}$ downstream of the thruster exit plane indicated plasma number densities on the order of $5 \times 10^{9} / \mathrm{cm}^{3}$ at electron temperatures less than $1.0 \mathrm{eV}$. The exhaust is only slightly ionized ( $<1$ percent). An increase in measured plasma number density was observed with increasing arc current at a constant mass flow rate and also with an increasing mass flow rate at constant current. Radial measurements $18 \mathrm{~cm}$ downstream of the thruster exit plane 
indicated that the plasma number density decreased exponentially. off centerline while values of electron temperature remained relatively constant with radial position. Similarly, an axial. survey of the plume centerline revealed that the plasma density decreased as the inverse of the distance squared.

This paper focuses on potential communications impacts due to the induced environment of an arcjet plume. Due to physical limitations of a spacecraft structure, it may be necessary for uplink and/or downlink common carrier signals to be transmitted through a portion of the plume, as illustrated in figure 1. The interaction of the radio frequency (RF) signal and the charged species of the plume must be well understood. Typical RF signal-plasma interactions include: reflection of the transmitted signal at the vacuum-plasma boundary, attenuation and phase shift, and generated noise on both signal amplitude and phase.

Potential arcjet plume impacts are difficult to quantify. However, the interaction between a plasma exhaust and common carrier signals has been studied previously (ref.s. 4 and 5). During the Solar Electric Propulsion development program, the transmission of $2.2 \mathrm{GHz}$ signals through a $30 \mathrm{~cm}$ mercury ion thruster exhaust was investigated both analytically and experimentally. It was reported that signal amplitude loss and phase advance increased with ion beam current: Maximum transmission loss was measured at $0.38 \mathrm{~dB}$ or 8 percent. Phase shifts advanced as high as $67^{\circ}$, although the effect of this shift was only significant during fast ion beam transients. No additional noise was observed on the carrier frequency during normal thruster operation, and the carrier frequency was not offset due to plasma effects. Poor space simulation may have existed in the experiments due to exposed metal vacuum tank surfaces causing signal reflections and an abnormal EM environment. Further, it was concluded that improvements in the analytical modeling of the plume electron density distributions and RF beam spreading were needed to confidently predict RF signal-plume interactions.

This paper presents a first order evaluation of the potential impacts of the arcjet thruster plume on communications. Assuming that gas dynamic expansion, rather than recombination, predominates in the far flow field plume, a two parameter equation (ref. 6) may be used to mathematically represent the electron number density distribution in the arcjet exhaust. Available experimental data are used to determine the values of the plume parameters. The interaction of the plume with a communications signal may then be evaluated by treating the plume as a homogeneous; isotropic plasma which perturbs the existing electromagnetic field state in space. The two primary properties which affect the steady state interaction are electron number density and temperature. Other factors include the RF power density and frequency, the propagation path (spacecraft geometry), static magnetic field intensity, and ion density and mass.

The first portion of this paper summarizes the basic theory for the interaction between a plasma and a radio frequency signal. The rationale for and the application of a source flow, two parameter equation to mathematically represent the arcjet plume is al so presented. Comparisons are made between the analytical model and experimental profiles. Using a realistic space flight geometry, the communications impact is then evaluated for a $4 \mathrm{GHz}$ signal transmitted along propagation paths running parallel to and intersecting the plume centerline. Transmission attenuation and phase shift are presented as a function of propagation path. 
NOMENCLATURE

A location of antenna behind arcjet nozzle exit plane, m

$A(N, \lambda)$ plume normalization constant (eq. (10)) .

B distance of antenna away from plume axis, m

c speed of light, $\mathrm{m} / \mathrm{sec}$

D assumed plasma slab dimension, $m$

$D_{a} \quad$ antenna aperture dimension, $m$

$D_{p} \quad$ Langmuir probe diameter, $m$

e fundamental charge, $C$

$f(\theta)$ functional distribution of density

I current, A

$L \quad$ distance from antenna aperture to vertex, $m$

m charged specie particle mass, $\mathrm{kg}$

M simplifying relation for $(1 / \mu-1)$

n number density, particles/m3

$\bar{n} \quad$ source number density, particles/m ${ }^{3}$

N plume parameter

$n_{c} \quad$ critical electron number density, electrons $/ m^{3}$

P $\quad 2 \times$ the entrance ordinate (geometrical optics approx.), $m$

$r \quad$ radial distance from arcjet source, $m$

$R$ radius from plume centerline, $m$

$\mathscr{R}$ distance from antenna aperture to center of plasma, $m$

$R_{e}$ exit radius of nozzle, $m$.

$T$ transmission loss, $\mathrm{dB}$

v. velocity, $\mathrm{m} / \mathrm{sec}$

$V$ voltage; $V$

$v_{p}$. probe voltage, $v$ 


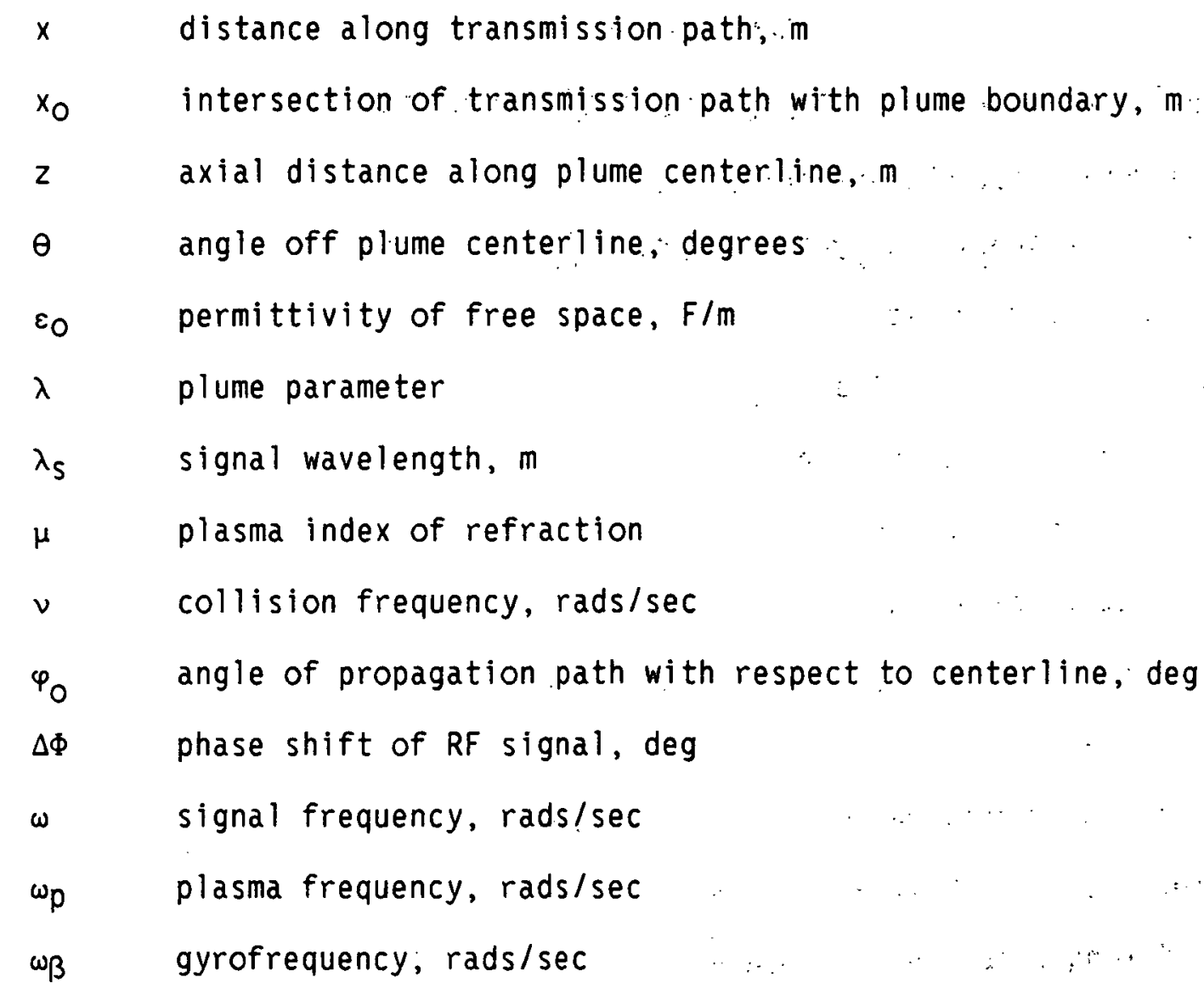

Subscripts or Superscripts:

$\begin{array}{ll}\text { a } & \text { arc } \\ \text { e } & \text { electron } \\ \text { lim } & \text { ion } \\ \max & \text { maximum } \\ \text { o } & \text { centerline } \\ \text { p } & \text { plasma }\end{array}$

ANALYSES

RF Signal-Plasma Interaction

Free electrons in the plume, because they are lightweight and very mobile, are the major source of interaction with RF transmissions as they readily absorb more energy than ions. However, at low frequencies, particularly below $500 \mathrm{MHz}$, the ion contribution also becomes important. RF transmission loss and phase shift result from a combination of physical processes including reflection of the signal at the vacuum-plume boundary, absorption, and refraction. 4 
Reflection of the transmitted signal by the plume depends upon the dielectric characteristics of the plume boundary. Generally, if the plume characteristics vary gradually near the boundary, the plume may be assumed to be adiabatic and reflection losses are minimal. Absorption, or line-of-sight attenuation, removes energy from the signal while refraction (beam spreading) merely redirects the incident energy.

A detailed theoretical treatment of the interaction between a plasma and microwave transmission signals is given by Heald and Wharton (ref. 7). The following analysis simplifies the interaction through the use of several critical plasma assumptions. A complete discussion of the limitations and validity of these assumptions will be presented later. As described by reference 7, the plume may be treated as a homogeneous, isotropic plasma which perturbs the existing electromagnetic field state in space. In a uniform medium without a magnetic field, a complex dielectric constant may be used to describe the propagation of plane electromagnetic waves. For a signal frequency $\omega$, a critical number density $\mathrm{n}_{\mathrm{C}}$ is defined by

$$
n_{c} \equiv \frac{\varepsilon_{o}^{m \omega}}{e^{2}}
$$

For $n<n_{c}$, the plasma behaves as a nearly transparent dielectric; for $n>n_{c}$, the medium is totally reflecting. When the signal frequency is greater than the plasma frequency, the plasma is a relatively low-loss dielectric. In. the $1 \mathrm{imit}$ where the square of the effective collision frequency $v^{2} \ll \omega^{2}-\omega_{p}{ }^{2}$ and $v^{2} \ll \omega^{2}\left(\omega^{2}-\omega_{p}^{2}\right)^{2} / \omega_{p} 4$, the plasma index of refraction (real) is

$$
\mu \approx \frac{\nu \omega_{p}^{2}}{2 \omega^{3}}\left(1-\frac{\omega_{p}^{2}}{\omega^{2}}\right)^{-1 / 2}
$$

where the index of refraction for a perfect vacuum is 1.0 .

Using a simple adiabatic analysis of a plasma slab, the phase shift caused by the presence of the plasma along a transmission path is

$$
\Delta \Phi=\int_{0}^{\infty} 1-\left[1-\frac{n_{e}(x)}{n_{c}}\right]^{1 / 2} \frac{2 \pi}{\lambda_{s}} d x
$$

where the propagation path extends from the transmitting to the receiving antenna. The shift is.a phase advance since the index of refraction of the plasma is smaller than unity. For $n<n_{c}$, the shift is linearly proportional to the electron number density averaged along the propagation path.

Assuming that the plasma is at a distance of at least one wavelength away from the antenna to avoid induction effects and the dimensions of the plasma are large in comparison to a wavelength, the geometrical optics limit is an appropriate approximation for: a two-dimensional analysis. The geometry is illustrated in figure 2. The plasma is assumed to be a uniform cylinder of diameter $D$ which constitutes a divergent cylindrical lens. The distance $P / 2$ 
is the entrance ordinate for the highest angle ray refracted by the plasma which would be received by, the antenna. The transmission:loss:due to refraction (assuming negligible absorption. and reflection), is written in terms of the ratio of power received by the antenna with and without the presence of a plasma. Specifically, the transmission ratio may, be written as

$$
T=\frac{\ddot{P}}{P(\mu=1)}=\frac{D(L+2 \dot{\mathscr{R}})}{4 M \mathscr{R}(L+\mathscr{R})+D(L+2 \mathscr{R})}
$$

where $M=1 / \mu-1$. For $P / D$ * $<1$; the cylinder is equivalent to a slab of thickness $D$. It is conventional to describe transmission loss in units of decibels where. $T$ in $d B=10 \mathrm{log}$ (transmission power ratio).

As mentioned previously, for $\omega \gg \omega_{p}$, absorption losses in the plasma may be assumed negligible. However, for comparison purposes, this transmission loss may also be calculated, in $d B$, using

$$
T, d B=-4.3 \frac{n_{e} / n_{c}}{\mu}\left(\frac{\nu D}{c}\right)
$$

Similarly, an estimate of the transmission loss due to reflection at the sharp vacuum-plasma boundary may be obtained by

$$
T=\left[1+\left(\frac{1-\mu^{2}}{2 \mu}\right)^{2} \sin ^{2}\left(\frac{2 \pi \mu^{D}}{\lambda_{s}}\right)\right]^{-1}
$$

where $P / D<1$ is the equivalent of a plasma slab.

\section{Flow Field Description of the Arcjet Plume}

A detailed numerical treatment of plume expansion requires an accurate description of the nozzle flow field as an input. The arcjet thruster is characterized by a nonequilibrium, highly viscous, compressible flow field where a considerable amount of heat addition occurs in the nozzle. Although computational methods exist to analyze the nozzle flow of higher thrust ( $) 22 \mathrm{~N}$ ) propulsion devices, the complex nature of arcjet gas/plasma dynamics and the small nozzle size precludes the immediate adaptation of conventional numerical techniques. In order to obtain reasonable predictions of the arcjet plume impacts, it is helpful to begin with source flow analyses.

In the far flow field, gas dynamic expansion, rather than recombination processes, dominates the plume expansion (ref. 8). The plasma density in the plume may then be treated as though it originated from a point source. Thus,

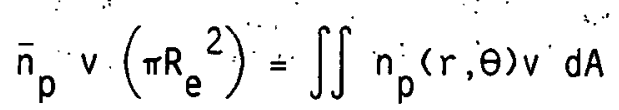

where $n_{p}$ is the source plasma density, $v$ is the species velocity, and $\mathrm{R}_{e}$ is the exit radius of the arcjet. nozzle... Because recombination of species in the near field of the arcjet source is -significant, the "source". density defined here is considered a virtual, source.

It is assumed that the density at any location in the plume $n_{p}(r, \theta)$ can be related to its centerline value $n_{p}\left(r, \theta=0^{\circ}\right)$ by a function $f(\theta)$. The two 6 
parameter, functional distribution of Reynolds (ref. 6), converted to spherical coordinates, is used, yielding the relation

$$
\frac{n_{p}(r, \theta)}{n_{p}\left(r, \theta=0^{\circ}\right)}=f(\theta)=e^{-\left\{[\lambda(1-\cos \theta)]^{n}\right\} / \cos ^{2} \theta}
$$

The values of the parameters $N$ and $\lambda$ are determined experimentally. Substitution of equation (8) into (7) gives the integral form,

$$
\overline{n_{p}} v\left(\pi R_{e}^{2}\right)=n_{p}\left(r, \theta=0^{\circ}\right) \int_{0}^{2 \pi} \int_{0}^{\theta} 1 i m v f(\theta) r^{2} \sin \theta d \theta d \varphi
$$

where $\theta_{1 i m}$ is the limiting angle to the flow of charged species.

Since the free electrons in the plume are the primary interaction mechanism, the subsequent analysis will consider only the electron number density distribution. As the electrons lose very little energy during expansion, the electron velocity remains relatively constant. Defining a plume normalization constant $A(N, \lambda)$ as

$$
A(N, \lambda) \equiv \frac{1}{2}\left[\int_{0}^{\theta} 1 \mathrm{im} \sin \theta f(\theta) d \theta\right]^{-1}
$$

the plume structure, based on this far field approximation; is described by

$$
\frac{n_{e}(r, \theta)}{\overline{n_{e}}}=A(N, \lambda)\left(\frac{R_{e}}{r}\right)^{2} f(\theta)
$$

Figure 3 presents normalized profiles of electron number density as a function of the angle off centerline for several values of $\lambda$ where $N=0.8$ and 1 . For a given value of either $N$ or $\lambda$, increasing the other parameter describes a more confined plume profile.

\section{Estimation of Arcjet Plume Communications Impacts}

Communications satelitites are generally located in geostationary orbits so that their position relative to a viewer on earth remains constant. Typical communication frequency pairs are at 4 and $6 \mathrm{GHz}$ and at 12 and $14 \mathrm{GHz}$. The lower value of each pair is always used as the downlink transmission frequency because the absorption characteristics of the atmosphere increase with frequency. It is noteworthy that, while the atmosphere absorption impacts increase with frequency, the effect is opposite with a plasma. This is due to the fact that the refractive index for a plasma, in contrast to typical dielectrics, is less than unity. As shown in equations (1) and (2) for a given $n_{e}$, the index of refraction approaches unity as $n_{c}$ (or rather, $\omega^{2}$ ) increases. $A$. $4 \mathrm{GHz}$ signal $\left(\lambda_{S}=7.5 \mathrm{~cm}\right.$ ) was used in this analysis as it represents the worst case.

Typically, core structures for communications satellites have dimensions on the order of a few meters. Figure 4 illustrates the thruster/antenna con 
figuration used in this analysis. The distance $A$ corresponds to the location of the antenna behind the thruster exit plane while $B$ denotes the distance away from plume centerline. The angle $\varphi_{0}$ denotes the angle of the propagation path with respect to centerline, where $\varphi_{0}=0^{\circ}$ corresponds to a line of sight parallel to the plume centerline and $\varphi_{0}=+76^{\circ}$ corresponds to intersection of the RF signal and the plasma source. The antenna and the thruster lie in the same plane. Calculations were made for propagation paths running both parallel to and intersecting the plume centerline. For the first case, $A$ and $B$ were constant and the angle $\varphi_{0}$ was varied; in the second case, A was constant and $B$ was allowed to vary away from thruster centerline with $\varphi_{0}=0^{\circ}$.

The parameters listed in table I were used to define the representative arcjet plume for the two cases. Using equation (11), the electron number density was then calculated at discrete intervals along a given propagation path. The phase shift was obtained by direct numerical integration of equation ( 3 ). Although the electron number density varied significantly along a given propagation path, the transmission attenuation was calculated by treating the plume as a plasma slab of uniform density. The relevant plasma dimension (diameter or slab thickness) was determined by calculating the distance over which the density decreased by a factor of 10 . The sensitivity of the calculations to the selection of plasma dimension will be presented later.

It was desired to investigate only the RF signal-plasma interaction and not antenna-specific effects that become important during actual thruster. integration. Therefore, the antenna size and placement selected for the analyses were such that it could be assumed that the interaction occurred in the antenna far field, that there were no induction effects, and that the entire RF beam intersected the plasma. Also, it was assumed that the RF power was low enough so that a linear variation of power density existed in the plasma; i.e., the RF signal did not perturb the plasma medium. A list of the major assumptions used in the plasma model and the calculations to follow may be found in table II, along with the criteria necessary to prove the validity of each assumption.

\section{APPARATUS AND PROCEDURE}

The Langmuir probe is a well established technique for the measurement of plasma properties (refs. 9 to 11). A previous investigation (ref. 3) has explored the application of the Langmuir probe to the measurement of plasma number density and temperature in the arcjet plume. Briefly, the Langmuir probe is simply a conductive element of known geometry which is connected to a power supply capable of biasing the probe to voltages both positive and negative with respect to the plasma to be investigated. The current drawn to the probe as a function of applied voltage yields fundamental information on the plasma properties, primarily electron number density and temperature.

A spherical Langmuir probe with a diameter of $6.35 \mathrm{~mm}$ was used to obtain radial profiles of electron number density at various distances downstream of the arcjet nozzle exit plane. It has been shown (ref. 3) that the ratio of electron number density to the centerline value may be obtained with reasonable accuracy by monitering the electron, current collected by probe at a voltage positive with respect to plasma potential. To avoid the necessity of taking discrete $V$-I characteristics at each measurement position, this method was used to obtain the profiles: A complete V-I characteristic was obtained on centerline at $z=18.4 \mathrm{~cm}$. 
The arcjet thruster was a laboratory model (ref. 3), operating on a $1: 2$ mixture of nitrogen to hydrogen to simulate fully decomposed thydrazine. For: the data presented, the arcjet thruster:operating conditions are given in table III. The arcjet anode was connected to facility ground.

\section{RESULTS: AND D.ISCUSSION}

This section presents a comparison between measured electron number density profiles and the source flow analysis.. An explanation for the unusual distribution function of plasma number density is proposed. The interaction of a $4 \mathrm{GHz}$ signal transmitted through a plasma with properties characteristic of an arcjet plume is then analyzed by modelling the arcjet plume as a plasma slab. The relative importance of the dominant loss mechanisms are compared, and illustrations of the number density profiles that selected propagation paths would encounter are presented. Finally, an evaluation of the transmission impacts is provided in terms of signal attenuation and phase shift. The impacts are presented as a function of propagation path for signals running both parallel to and intersecting the plume centerline.

\section{Comparison of Experimental. Profiles with. Two Parameter Equation}

Figure 5 compares calculated number density profiles, normalized to the centerline value, with experimental data. The profile data: were obtained by measuring the electron current collected by the Langmuir probe at an applied voltage of $+3 \mathrm{~V}$. Measurements were made at various distances downstream of the thruster exit plane. Table III lists the arcjet operating conditions and plasma plume parameters for the comparison. A complete V-I characteristic obtained at the centerline position for, $z=18.4 \mathrm{~cm}$ yielded an electron number density of $7 \times 10^{9} / \mathrm{cm}^{3}$. The values of the plume parameters which best describe the profile data taken at $z=18.4$ and $28.6 \mathrm{~cm}$ are $N=0.8$ and $\lambda=4$. With appropriate selection of $N$ and $\lambda$, there is very good correspondence between the experimental data and the analytical approximation in the far field. In the near field, the centerline values also agree reasonably. well, as shown in figure $5(c)$, but the parametric equation greatly overpredicts the electron number density along a radius when the axial dis.tance: $z$ is less than $10 \mathrm{~cm}$. The values of $N$ and $\lambda$. which would provide a best fit of the data at $z=8.3 \mathrm{~cm}$ are 0.9 and 7 , respectively.

An estimate of the background plasma number density is also shown in figure 5 as $10^{8} / \mathrm{cm}^{3}$. The measured number density reached the background plasma density at radial distances corresponding to an angle of about $75^{\circ}$. A complete vacuum expansion would probably show a decrease in density beyond $75^{\circ}$. Measurements of the arcjet plume expansion in a facility of higher vacuum will provide a more accurate description of the high angle variation in plasma density.

Unlike traditional source flow descriptions of plumes, the arcjet plume is characterized by a slowly decaying; : exponential decrease in electron number density off centerline. In addition, the heavy particle ions follow the same radial pattern as the electrons. This is in direct contrast to the highly confined plumes of chemical rockets or ion thrusters where'a cosine distribution would provide a better description of the angular variation of density (refs. 6 and 12$)$. A cosine distribution is equivalent to values of $\lambda>20$ in the function $f(\theta)$ given by equation (8). This latter situation is illustrated in 
figure $3(a)$ using $\lambda=100$. However, cumulative arcjet plume data have indicated values of plume parameters ranging from $N=0.7$ to 1.0 and $\lambda=3$ to 7 . There are two possible reasons for the observed gradual decrease in plasma number density off centerline: (1) facility effects are dominating the expansion process; or (2) the functional description is real and valid and is a result of the complex, highly viscous flow generated in the arcjet nozzle. Both possibilities deserve comment.

Firstly, although the facility pressure is relatively high $\left(2 \times 10^{-4}\right.$ Torr), the location of the first mach disk is greater than $100 \mathrm{~cm}$ downstream of the thruster exit plane. It does not seem likely that the background pressure is affecting measurements within $65^{\circ}$ of centerline and certainly not within $40^{\circ}$ where a cosine distribution would be readily apparent. Secondly, it seems unlikely that inelastic collision processes would alter the charged specie distribution since the collision frequencies for excitation and charge exchange are relatively small (ref. 3). Typical mean free paths for inelastic collisions are on the order of $10^{5}-10^{7} \mathrm{~cm}$.

One plausible explanation for the exponential profiles is that the plasma distribution is a direct consequence of the highly viscous flow generated in the arcjet nozzle. For comparison, it is worthwhile to examine an alternate plume model. The semi-empirical method of G.A. Simons is a widely used technique for the prediction of a rocket plume structure (ref. 12). The method accounts for the expansion of the viscous, supersonic boundary layer in addition to the inviscid core of the nozzle. It is an analogous technique to that of Reynolds (ref. 6) except that the major plume parameters are written in terms of conditions at the nozzle exit plane and boundary layer thickness rather than relying on experimental data obtained in the plume. Simons determined that the appropriate selections for the function $f(\theta)$ were: (1) a cosine distribution for the flow in the plume which originates from the inviscid core, and (2) an exponential decay for flow which originates from the viscous, supersonic boundary layer. No provision was made for subsonic boundary layer expansion. The low power arcjet thruster is characterized by highly viscous nozzle flow. Under typical operating conditions, the Reynolds number, based on throat diameter, is $<500$. One consequence of low Re nozzle flow is that the boundary layer makes up a large portion of the nozzle volume and, in some cases, may engulf the inviscid core. As the analysis of simons indicates, viscous flow generated in the nozzle decreases less rapidly in the plume than does core flow, providing an explanation for the exponential decay in arcjet plasma density.

\section{Plume Impacts Assessment}

Figure 6 displays the relative importance of the three major sources of signal attenuation for a $4 \mathrm{GHz}$ signal transmitted through a typical arcjet plasma. For the assumed plasma conditions, the refraction loss dominates except for densities approaching the critical: number density. The reflection loss, shown in the figure as a function of $n_{e} / n_{c}$. only, is the absolute worst case, i.e., there is no provision for a slab thickness as in the impacts calculations to follow. In practical application where a slab dimension $D$ has been defined, the transmission ratio is an oscillatory function which varies between $\left(2 \mu /\left(1+\mu^{2}\right)\right)^{2}$ and 1 as the relative phasing of internal reflections changes. 
It should be noted that dissipative losses remain low even at high $n_{e} / n_{c}$ ratios. The effective collision frequency (assumed here to be the electron-ion

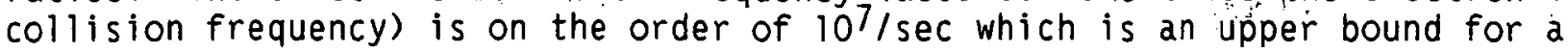
$1 \mathrm{~kW}$ arcjet plume. Because the dissipative losses are relatively small, absorption can be neglected for the situation proposed.

Figure 7 describes the arcjet piume structure based on the model input conditions listed in table I. Plotted in the figure are lines of constant electron number density emanating from the arcjet source: The unusual contour shape at large angles from centerline is a result of the exponential shape function. As mentioned previously, for $z<10 \mathrm{~cm}$, the calculated values of electron number density are higher than experimental observations.

The calculated electron number density that a transmission signal would encounter is shown in figure 8 for two propagation paths. For paths which intersect the plume centerline, as illustrated by $\varphi_{0}=70^{\circ}$, the profile is highly collimated with the maximum number density near the center of the assumed plasma slab diameter $D$. For propagation paths which run parallel to the plume centerline $\left(\varphi_{0}=0^{\circ}\right)$ the maximum number density occurs at the plume boundary. The change in the refractive index over the distance of a wavelength is the primary cause of reflection at the vacuum-plasma boundary. The sharp rise in electron number density at the intersection of the plume boundary is a functional limitation of the modelling technique and is probably not real. However, it magnifies the reflection problem because, for propagation paths which pass near the arcjet source, the higher number density at the boundary implies significant reflection of the signal. Table III lists the necessary critteria for the validity of the RF signal-plasma interaction. model. Sample calculations are provided for the above propagation paths.

Figures 9 and 10 present the calculated transmission impacts in terms of signal attenuation and phase shift as a function of propagation paths running both parallel to and intersecting the plume axis. The signal loss due to. refraction (figs. $9(a)$ and $10(a)$ ) is presented in units of $d B$ where the transmission loss is the ratio of power received with the plasma present to the power received without the plasma. Except for propagation paths which pass very near the arcjet source, the transmission loss is negligible. For propagation paths which pass within $15 \mathrm{~cm}$ of the source, however, there is significant attenuation of the transmitted signal due to refraction of the beam. Although not indicated in the figure, reflection of the signal at the sharp plasma-vacuum boundary may also occur for paths close to the source, particularly for parallel propagation paths.

The calculated signal attenuation is relatively insensitive to the value of slab diameter chosen although, in general, the refraction loss increases with decreasing slab diameter. As an example, for the propagation path $\varphi_{0}=0^{\circ}$, the transmission loss for an assumed slab dimension $D$. of $542 \mathrm{~cm}$ is $-2 \times 10^{-4} \mathrm{~dB}$. For $D=50 \mathrm{~cm}$, the loss remains negligible at $-6 \times 10^{-3} \mathrm{~dB}$.

Figures $9(b)$ and $10(b)$ present the phase shift as a function of propagation path. The shift is a phase advance as the plasma index of refraction is less than unity. In contrast to transmission losses, the phase advance increases with increasing signal frequericy. Although there is a noticeable phase advance for all propagation paths, the shift is again most severe for paths which pass close to the thruster source. In the antenna far field, a phase shift of any magnitude is not significant unless only a portion of the 
plane wave:is. shifted in phase rather than the entire wavefront. Nonuniform phase shifts of this sort would limit receiver tracking capability:

As mentioned previously, the antenna dimensions and the thruster-antenna placement were selected such that the RF signal-plasma interaction occurred in the antenna far field. In actual flight application this assumption might not always be valid as the antenna dimensions may be on the order of $1 \mathrm{~m}$ or more. In the antenna near field, a complex numerical analysis is required to fully define the effects of RF signal-plasma interactions. For example, a phase shift of even a few degrees in the antenna near field could effectively distort the antenna reflector geometry with severe communications impacts.

\section{CONCLUDING REMARKS}

This paper has presented a first order evaluation of the potential interaction of a low plasma density arcjet plume with RF signals in common use on communications satellites. Modelling the plume as a plasma slab, the communications impact for a $4 \mathrm{GHz}$ signal was evaluated for propagation paths running both parallel to and intersecting the plume centerline. The impacts were presented in terms of signal attenuation and phase shift from transmitting to receiving antennae. The dominant transmission loss mechanism was refraction of the signal rather than absorption or reflection at the plasma-vacuum boundary. Unless the propagation path passes very close to the thruster source, there appears to be neglibile attenuation due to refraction. A phase advance was predicted for all propagation paths. However, in the antenna far field, a phase shift of any magnitude is not significant unless only a portion of the plane wave is shifted in phase rather than the entire wavefront.

The two parameter, source flow equation used in this analys is is adequate to conduct an initial assessment of the arcjet plume communications impacts. However, a thorough understanding of the dominant gas/plasma dynamic processes occurring in the arc discharge and nozzle regions is required before improvements to the plume model can be made. Also, an accurate prediction of plasma number density near the plume boundary is needed to fully evaluate the magnitude of signal reflection losses. It is suspected that a more gradual plasma. boundary exists but measurements in a facility of higher vacuum are needed to provide a better description of the complete expansion. Further, this analysis investigated only the far field interaction of a uniform plasma slab with an RF signal. A more rigorous calculation of the communication impacts would include the effects of a nonuniform plasma density distribution as well as the interaction processes which occur in the antenna near field. Second order impacts such as re-polarization of an EM wavefront would al:so be considered.

Lastly, future communications satellites will utilize higher frequency bands $(20$ and $30 \mathrm{GHz}$ ) for transmission. This technology advance reduces the impacts of-low power arcjet thruster plumes, because the signal attenuation impacts decrease with increasing signal frequency. However, the arcjet plume electron number density and temperature increases significantly with power level. As the arcjet thruster technology is scaled to increasing power levels to meet other space propulsion applications, it cannot be assumed that the two technology advances will off set each other in terms of plume impacts. In fact, it seems likely that dissipative effects due to collisions (absorption) will also have to be considered in the impacts evaluation of arcjet thrusters above a few $\mathrm{kW}$. 


\section{ACKNOWLEDGMENTS}

The author wishes to express appreciation to the following individuals:

Mr. John M. Sankovic of the University of Akron for his assistance in obtaining arcjet plume experimental data; and Dr. Denis J. Connolly, Dr. Charles A. Raquet, and Dr. Roberto J. Acosta of the NASA Lewis Research Center for valuable technical discussions on antenna and RF systems.

\section{REFERENCES}

1. Curran, F.M., and Haag, T., "An Extended Life and Performance Test of a Low Power Arcjet," AIAA Paper 88-3106, July 1988.

2. "Arcjet Thruster Research and Technology, Phase I, Final Report," 87-R-1175, Rocket Research Company, Redmond, WA, Sept. 1987.

3. Carney, L.M., "An Experimental Investigation of an Arcjet Thruster Exhaust Using Langmuir Probes," Master's Thesis, University of Toledo, NASA TM-100258, 1987.

4. Ackernecht, W.E., III, and Stanton, P.H., "The Effects of an Ion-Thruster Exhaust Plume on. S-Band Carrier Transmission," JPL-TM-33-754, 1976, Jet Propulsion Lab., Pasadena, CA, NASA CR-145919.

5. Stanton, P., "Ion Plume/S-Band Carrier Interaction Study," Experimental and Analytical Evaluation of Ion Thruster Spacecraft Interactions, M.R. Carruth, Jr., ed., JPL-PUB-80-92 (NASA CR-163975), Jet Propulsion Lab., Pasadena, CA, 1981, pp. 191-215.

6. Reynolds, T.W., "Mathematical Representation" of Current Density Profiles from Ion Thrusters," NASA TN D-6334, 197.1.

7. Heald, M.A., and Wharton, C.B., Plasma Diagnostics with Microwaves, John Wiley and Sons Inc., New York, 1965.

8. Malone, L.H., "Comparison of Electron-Ion Recombination and Gas-Dynamic Expansion Rates in Freely Expanding Helium and Argon Plasmas," AEDC-TR-76-34, ARO-ETF-TR-75-114, ARO Inc., Arnold Air Force Station, TN, Mar. 1976. (Avail. NTIS, AD-A021958.)

9. Laframboise, J.G., "Theory of Spherical and Cylindrical Langmuir Probes in a Collisionless, Maxwellian Plasma at Rest," UTIAS-100, University of Toronto Institute for Aerospace Studies, June 1964. (Avail. NTIS, AD-634596).

10. French, J.B., "Langmuir Probes in a Flowing Low Density Plasma," AFOSR-2159, UTIA-79, University of Toronto Institute of Aerophysics, Aug. 1961.

11. Sonin, A.A., "The Behaviour of Free Molecule Cylindrical Langmuir Probes in Supersonic Flows, and Their Application to the Study of the Blunt Body Stagnation Layer," UTIAS-109, University of Toronto Institute for Aerospace Studies, Aug. 1965. (Avail. NTIS, AD-626451). 
12. Simons, G.A.; "Effect of Nozzle Boundary Layers on Rocket Exhaust Plumes," AIAA Journal, Vol. 10, No. 11, Nov. 1972, pp. 1534-1535.

TABLE I. - ARCJET PLUME MODEL PARAMETERS AND THRUSTER-ANTENNA CONFIGURATION INFORMATION FOR IMPACTS EVALUATION

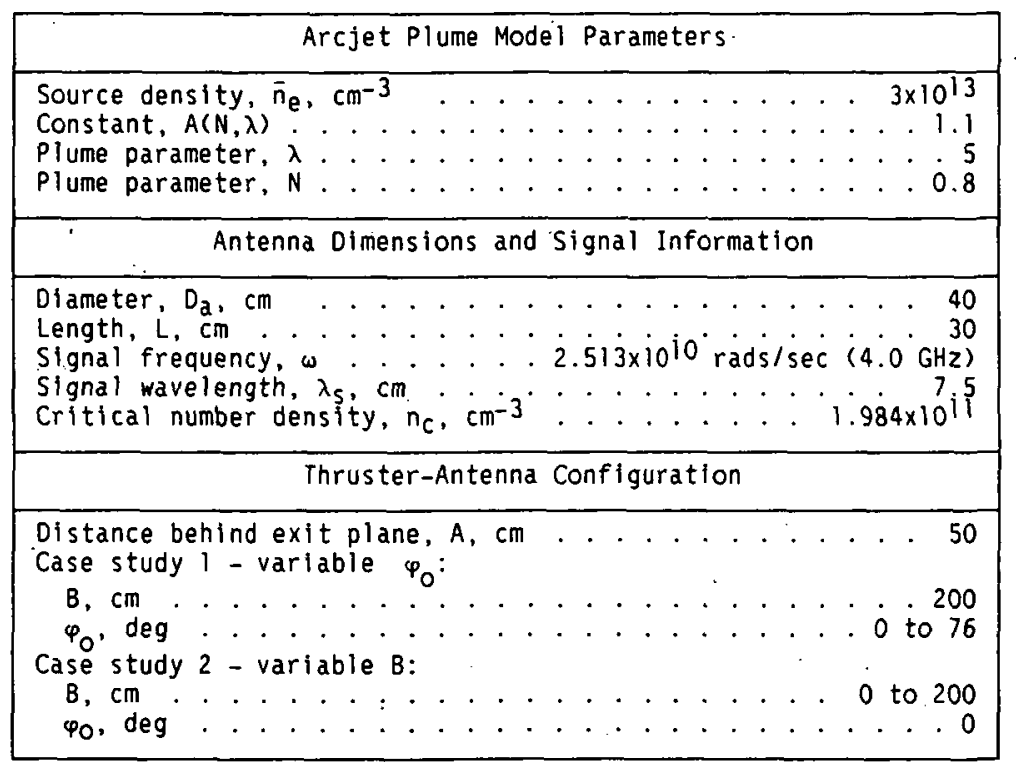


TABLE II. - ASSUMPTIONS NECESSARY FOR APPLICATION OF RF SIGNAL-PLASMA INTERACTION MODEL. SAMPLE CALCULATIONS ARE PRESENTED FOR TWO PROPAGATION PATHS.

$[A=50 \mathrm{~cm} ; B=200 \mathrm{~cm}$.

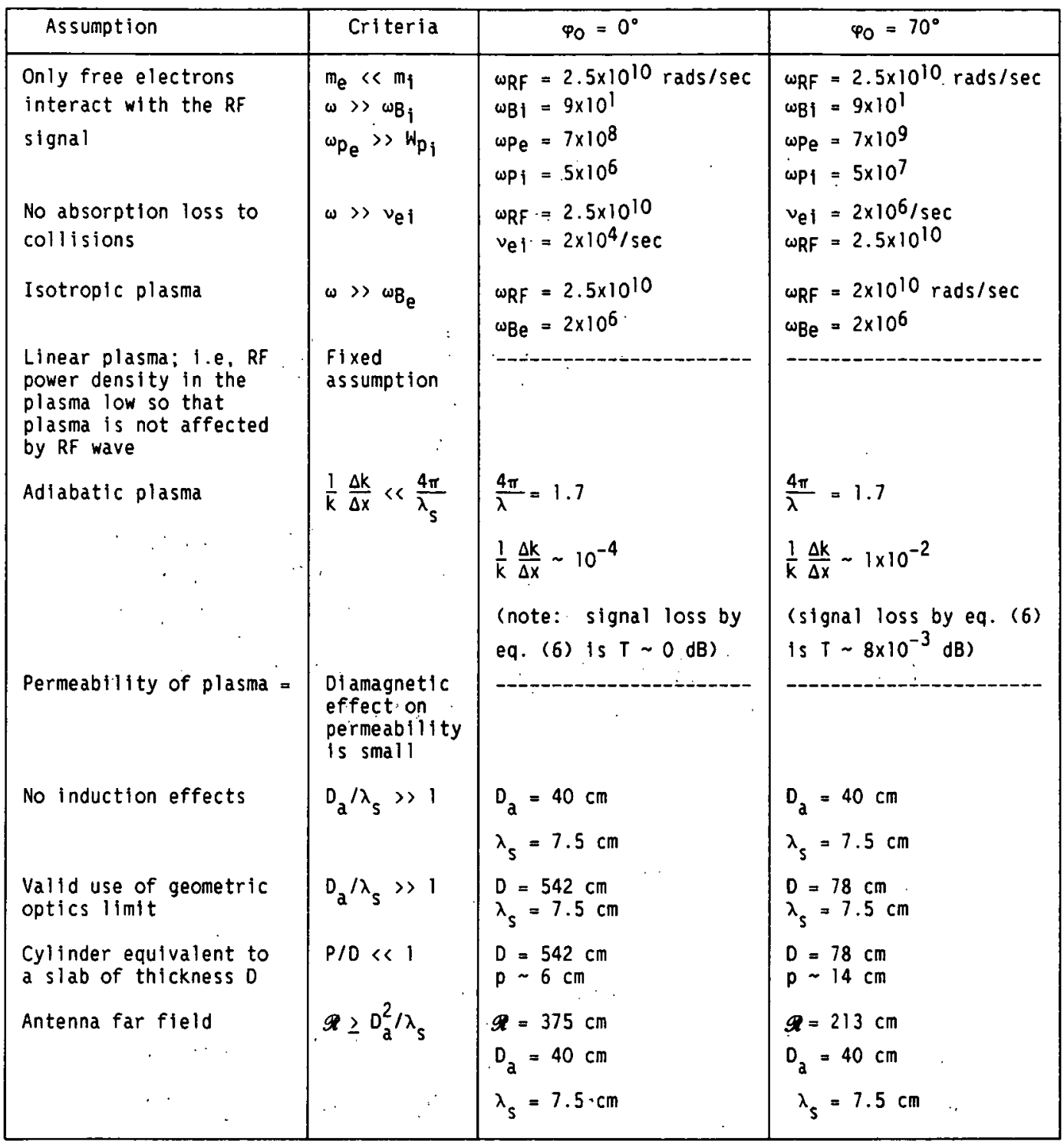

TABLE III. - ARCJET THRUSTER OPERATING CONDITIONS AND ASSUMED PLASMA PARAMETERS FOR COMPARISON OF SOURCE FLOW MODEL WITH EXPERIMENTAL DATA

\begin{tabular}{|c|}
\hline Arcjet thruster operating conditions \\
\hline $\begin{array}{l}\text { Arc current, } A \\
\text { Arc vol tage, } v \\
\text { Arc power, } W \\
\text { Mass flow rate }\left(1: 2 \text { mixture of } \mathrm{N}_{2}: \mathrm{H}_{2} \text { by volume }\right)\end{array}$ \\
\hline Assumed plume parameters for model comparision \\
\hline 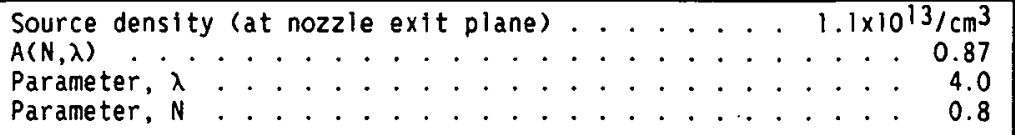 \\
\hline
\end{tabular}




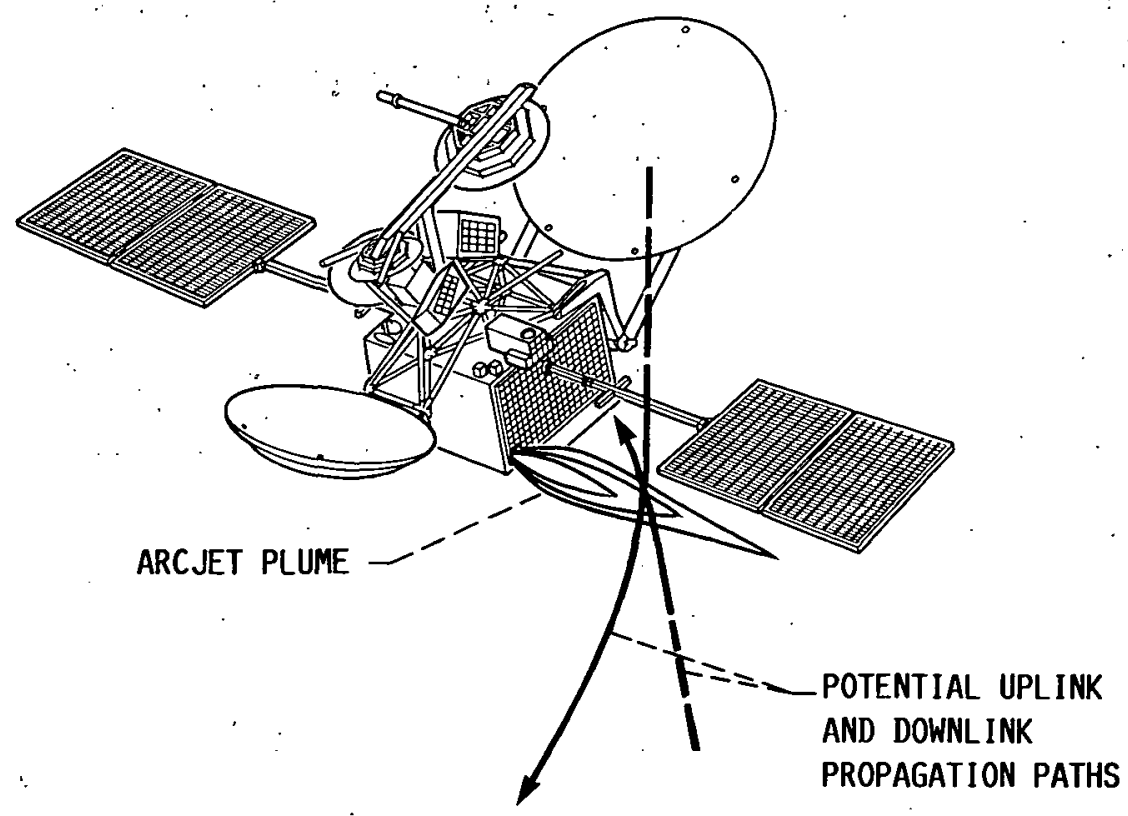

FIGURE 1. - ILLUSTRATION OF POTENTIAL ARCJET PLUME INTERACTION WITH THE TRANSMISSION OF COMMUNICATIONS SIGNALS.

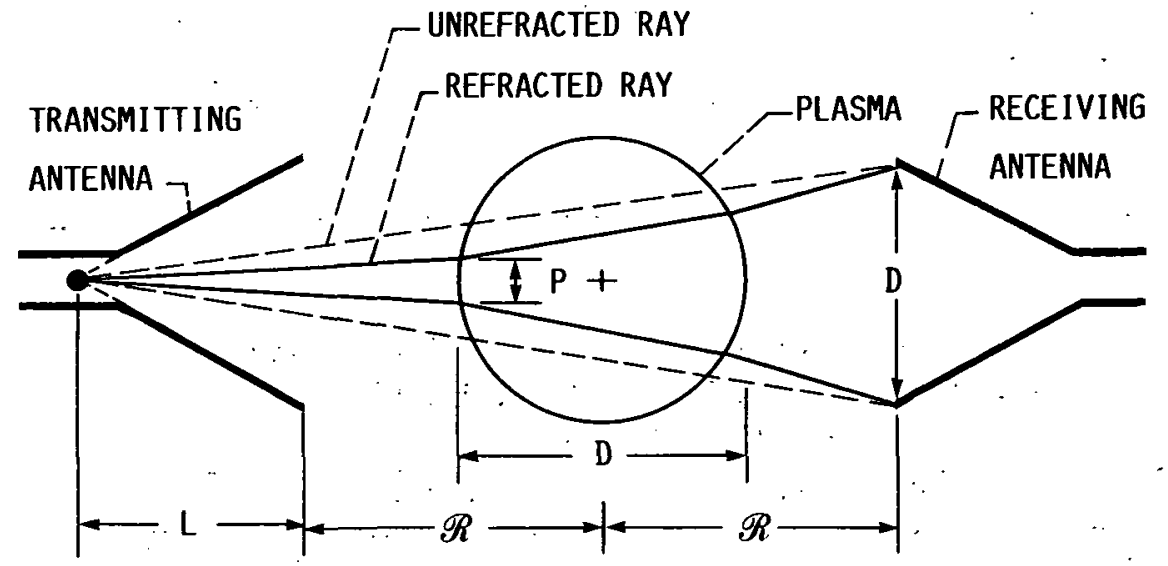

FIGURE 2: - GEOMETRICAL OPTICS APPROXIMATION FOR THE EFFECTS OF REFRACTION (ADAPTED FROM FIG. 4.10, REF. 7). 


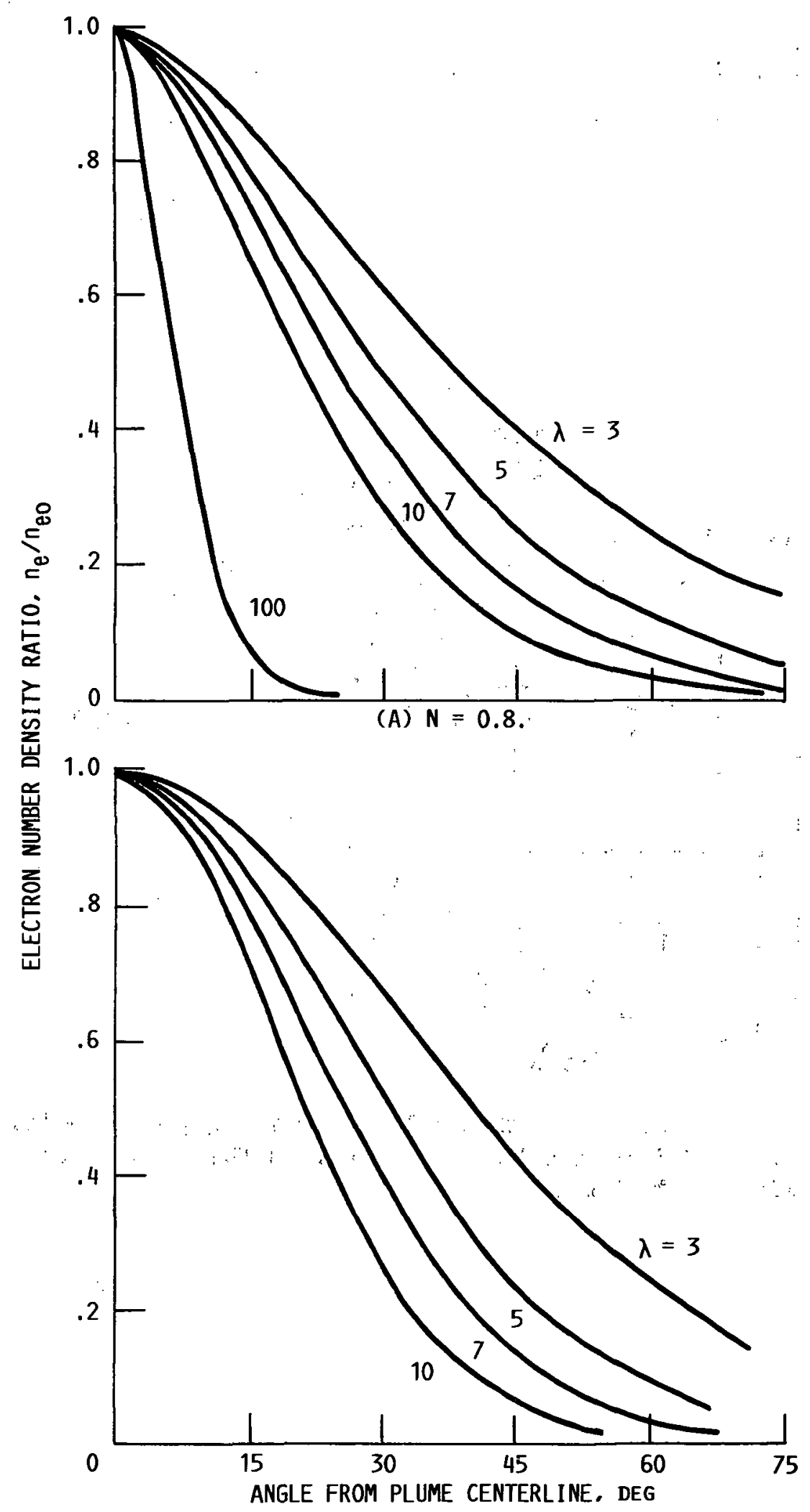

(B) $N=0.8$.

FIGURE 3. - PROFILE VARIATION WITH PARAMETER $\lambda$. 


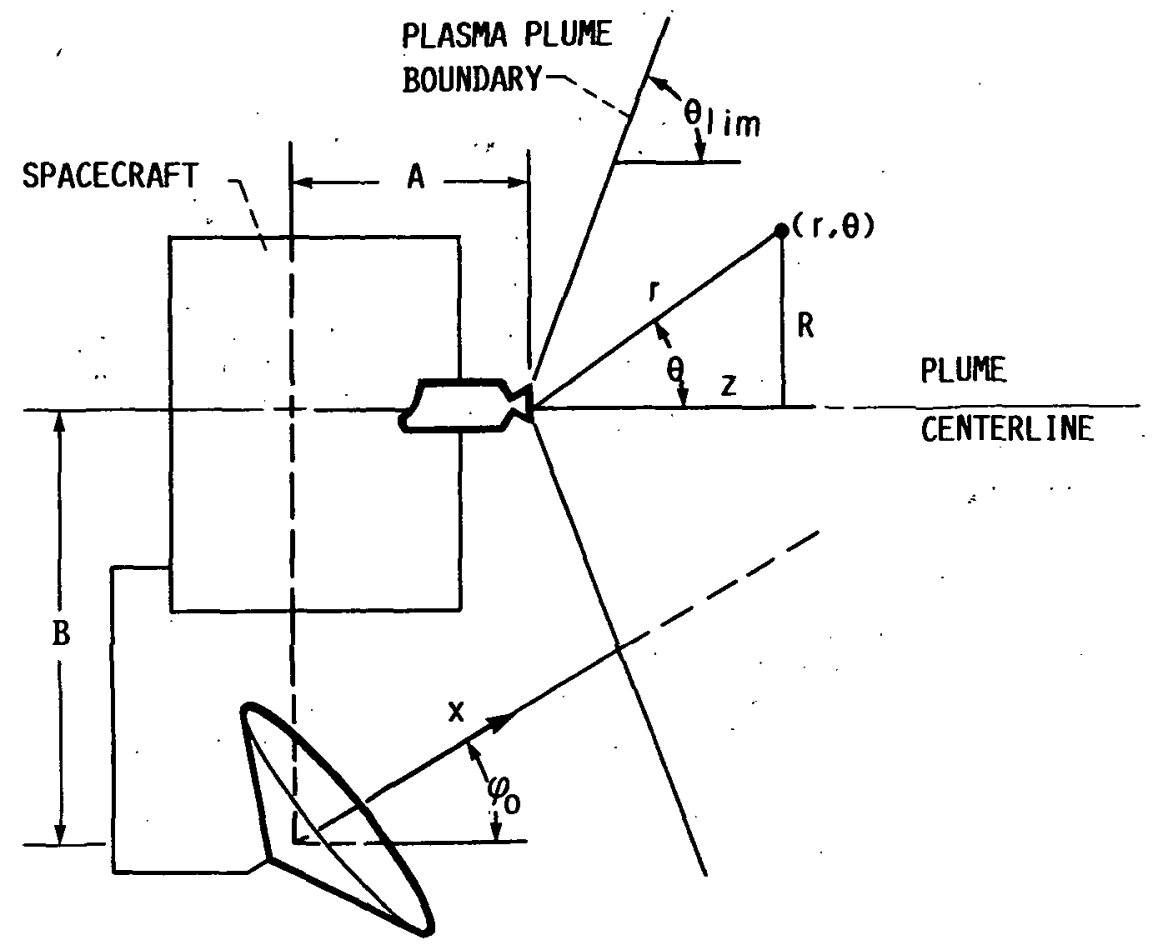

FIGURE 4. - ILLUSTRATION OF THRUSTER-SPACECRAFT CONFIGURATION FOR CALCULATIONS OF TRANSMISSION IMPACTS TO MICROWAVE SIGNALS DUE TO ARCJET PLASMA PLUME. 


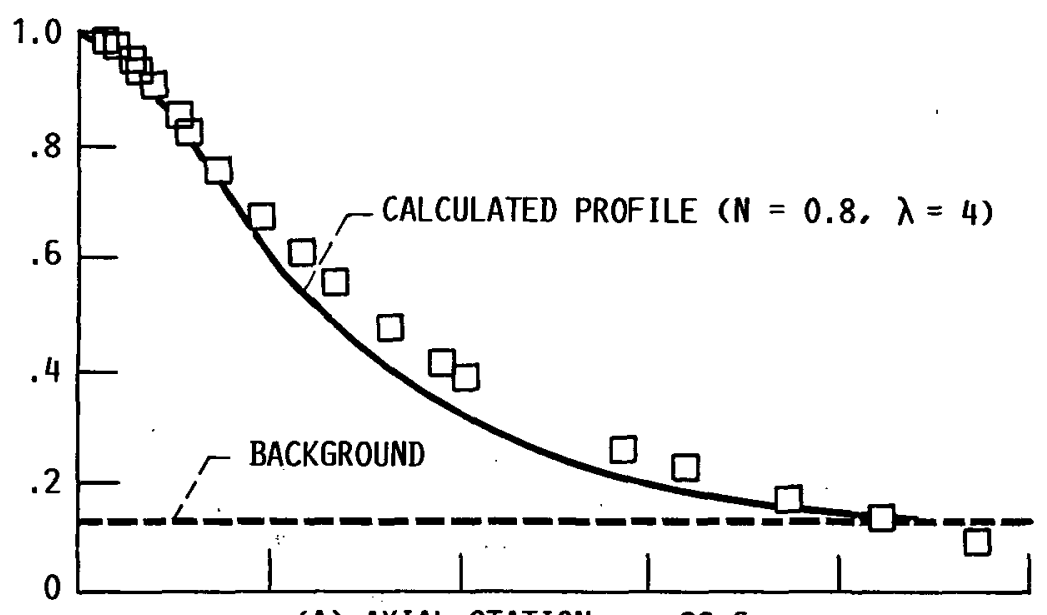

(A) AXIAL STATION $z=28.6 \mathrm{~cm}$.
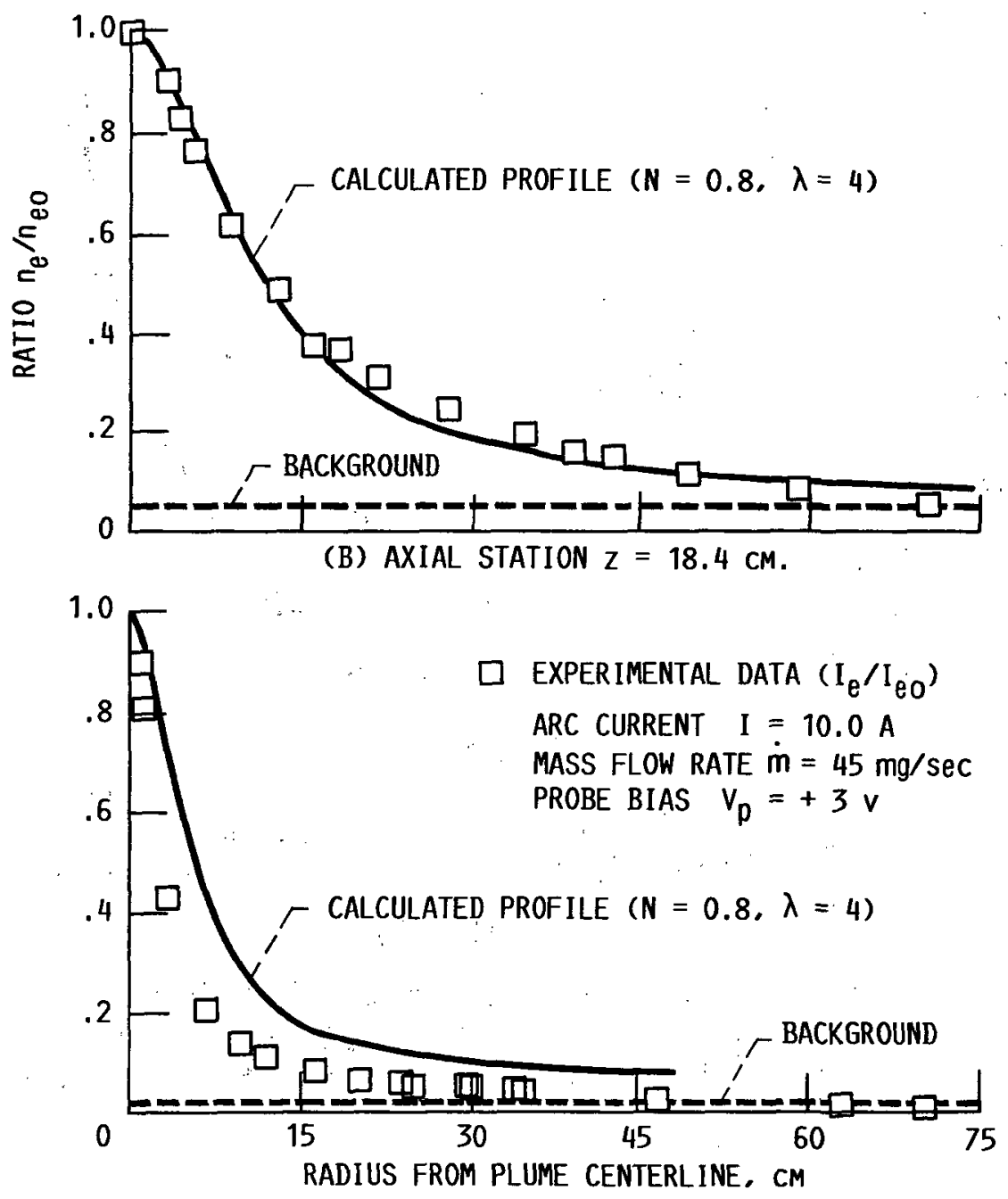

(C) AXIAL STATION $z=8.3 \mathrm{~cm}$.

FIGURE 5. - COMPARISON OF EXPERIMENTAL DATA WITH ANALYTICAL MODEL. EXPERIMENTAL PROFILES ARE BASED ON MEASURED ELECTRON CURRENT NORMALIZED TO CENTERLINE VALUE. 


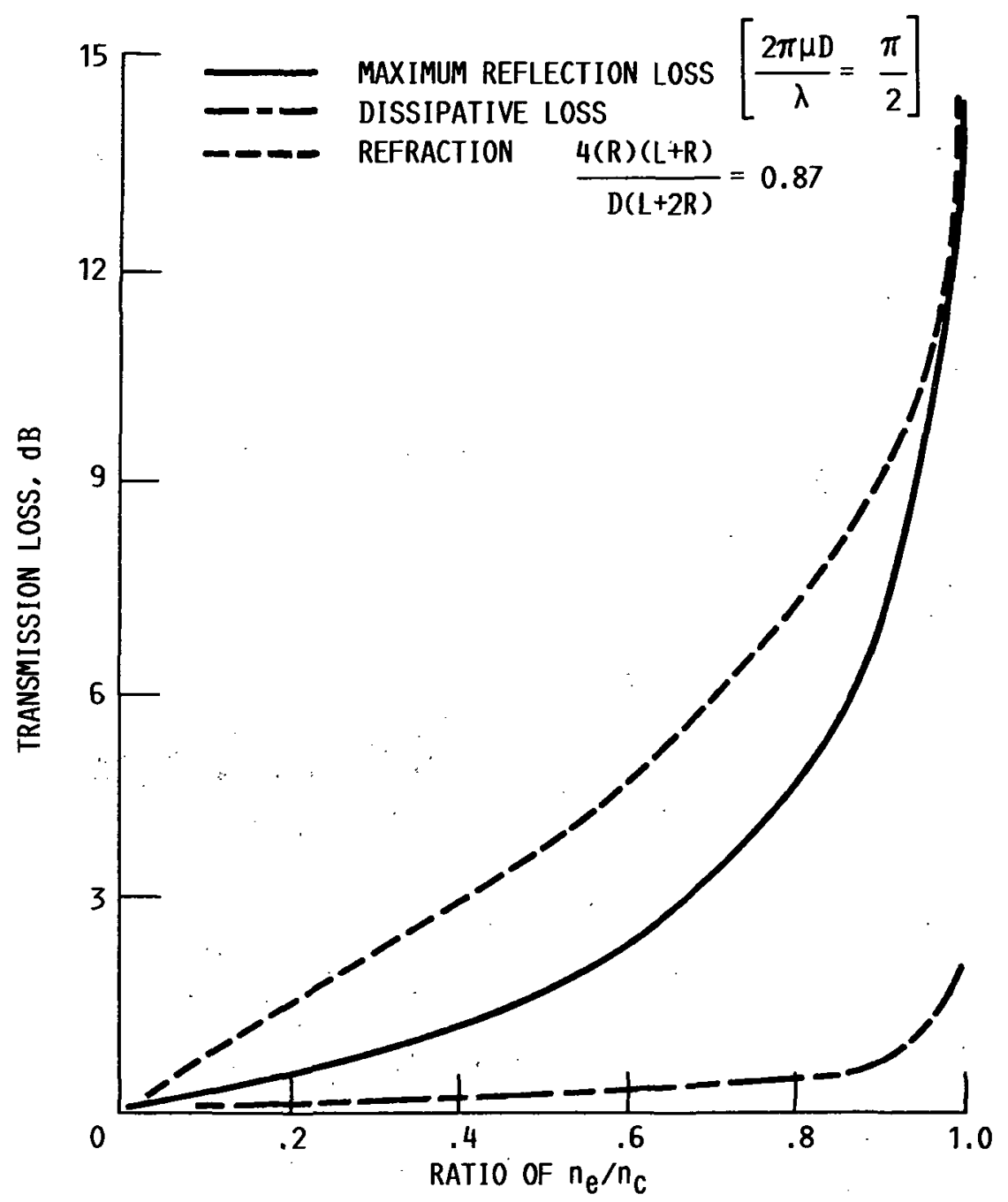

FIGURE 6. - RELATIVE IMPORTANCE OF SOURCES OF TRANSMISSION LOSS AS A FUNCTION OF $n_{e} / n_{c}$ FOR A PLASMA TYPICAL OF AN ARCJET PLUME $\left(V=4 \times 10^{6} / \mathrm{SEC} ; D=375 \mathrm{~cm}\right)$. 


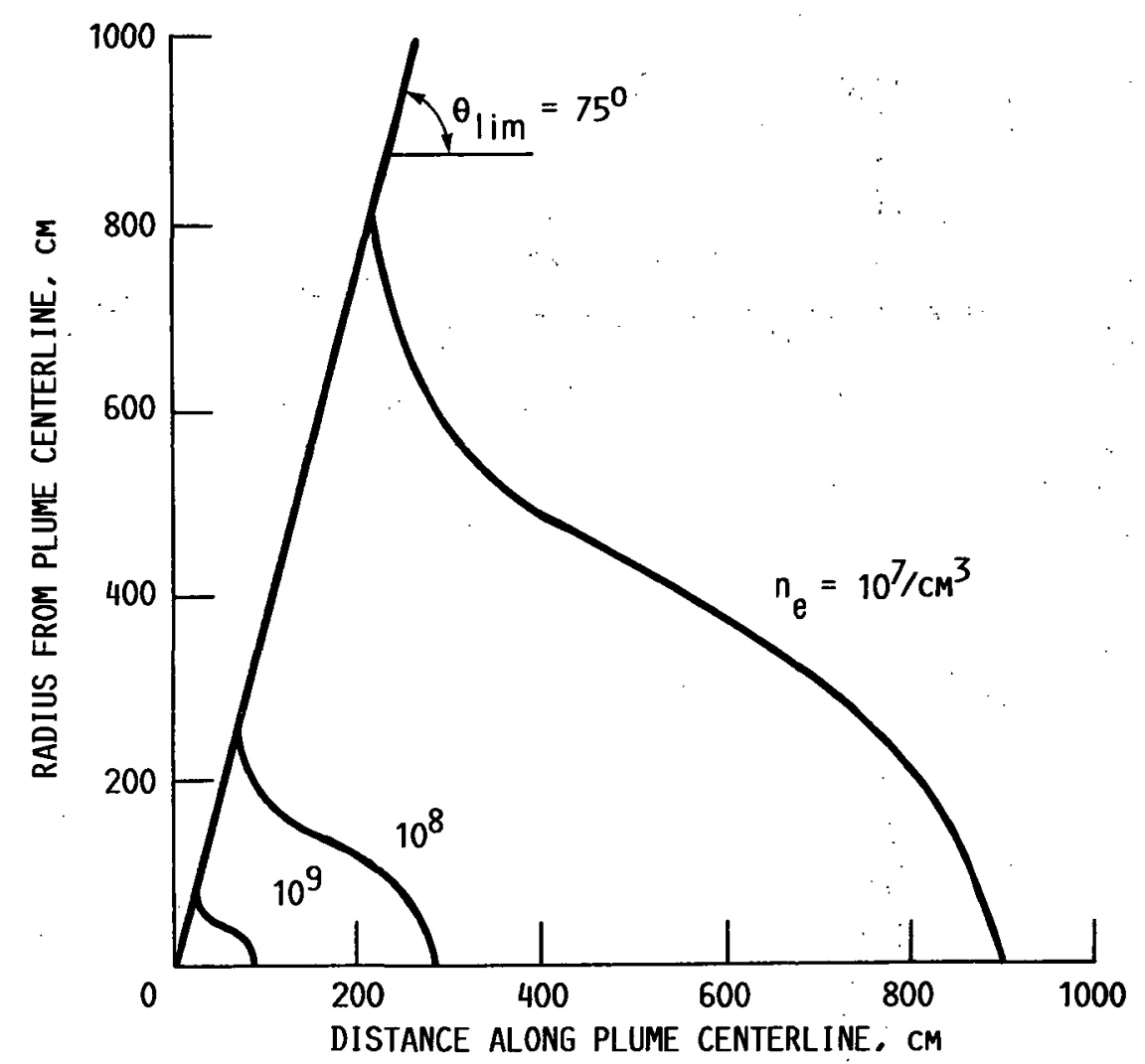

FIGURE 7. - CONSTANT NUMBER DENSITY CONTOURS. SOURCE DENSITY $=.3 \times 10^{13} / \mathrm{cm}^{3} ; N=0.8 ; \lambda=5$. 


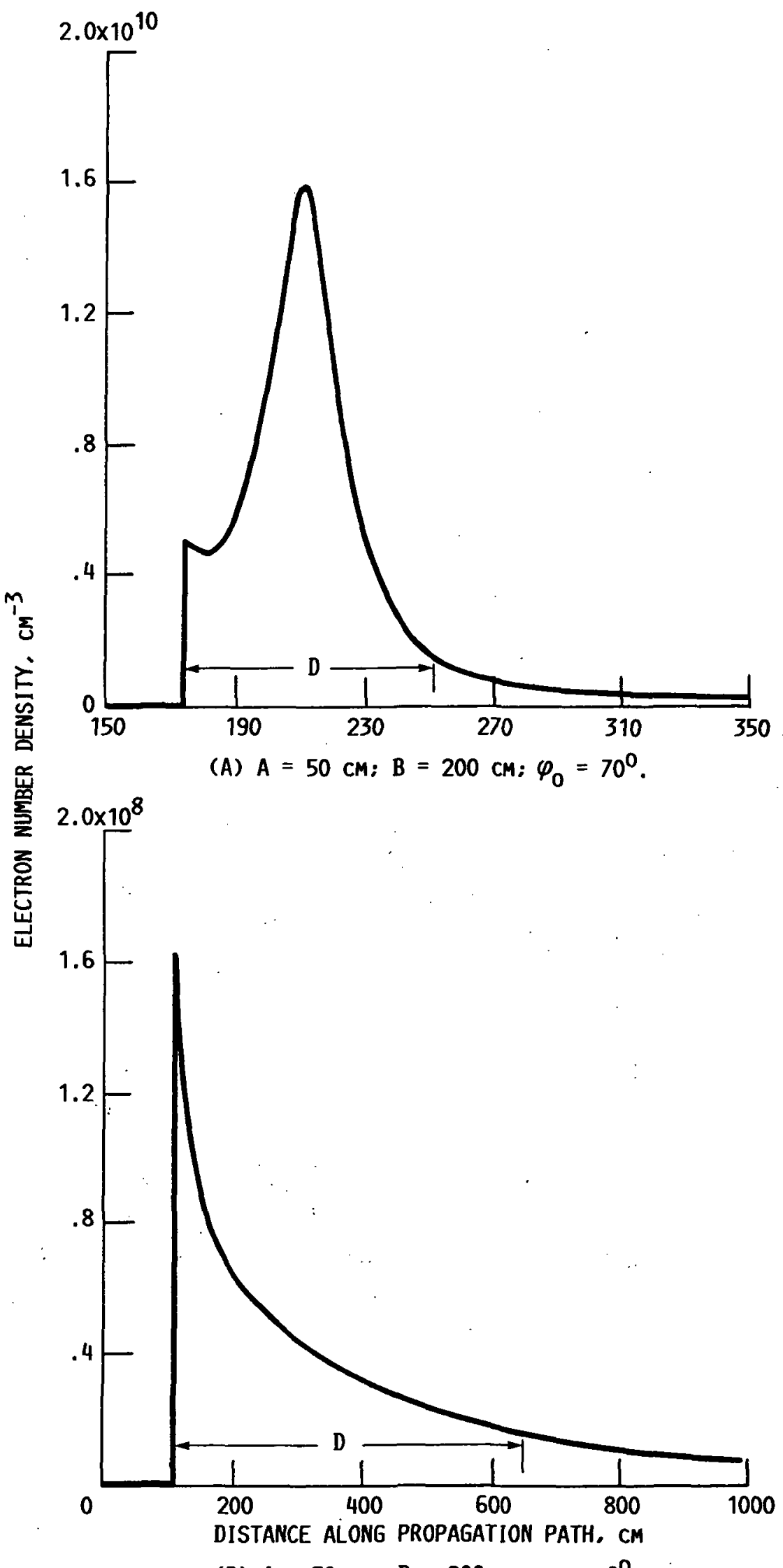

(B) $A=50 \mathrm{~cm} ; B=200 \mathrm{cM} ; \varphi_{0}=0^{\circ}$.

FIGURE 8. - ELECTRON NUMBER DENSITY ALONG PROPAGATION PATH. ANTENNA LOCATED AT $X=0 \mathrm{cM}$. 

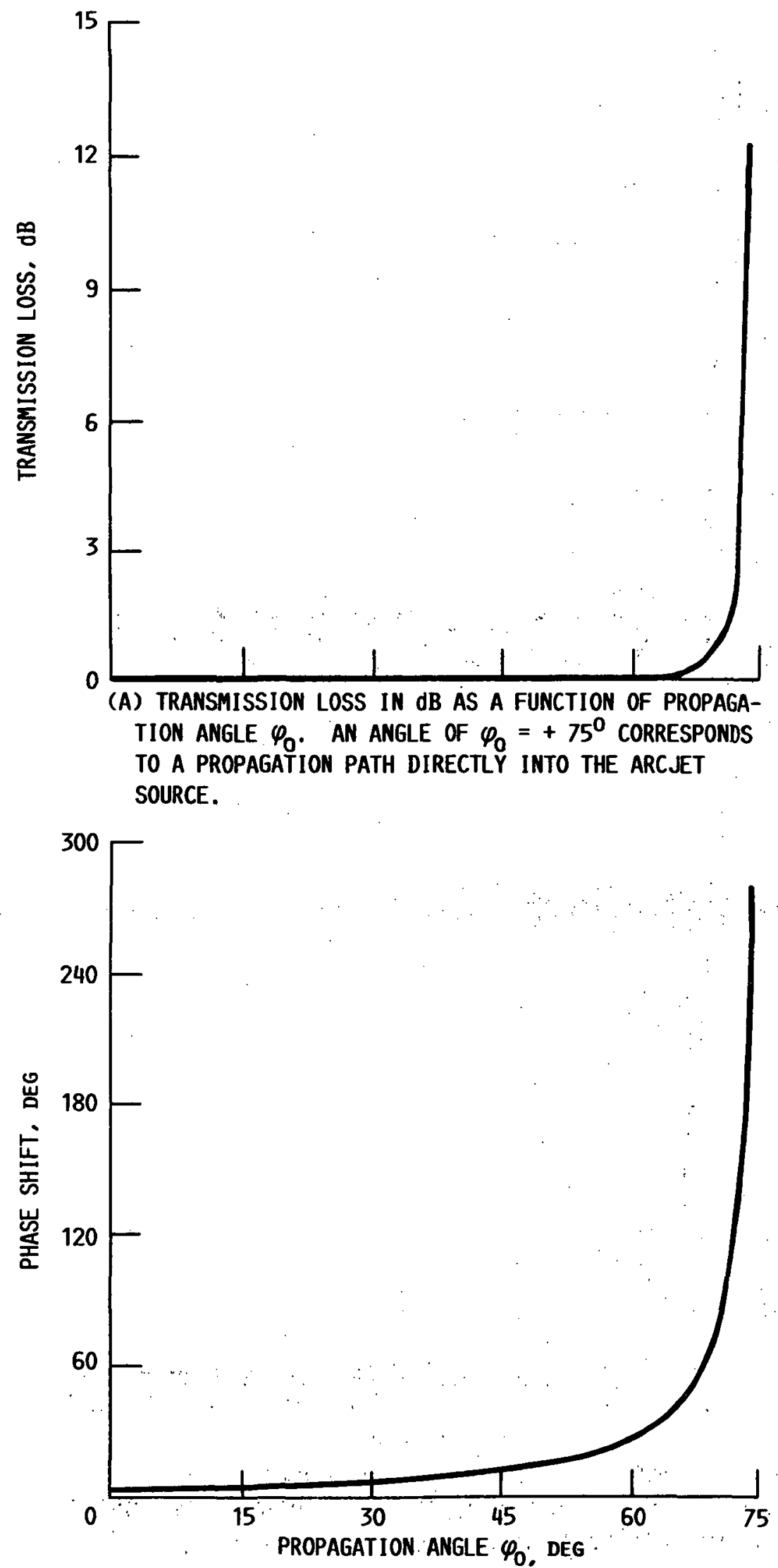

(B) PHASE SHIFT AS FUNCTION OF PROPAGATION ANGLE $\varphi_{0}$. FIGURE 9. - TRANSMISSION IMPACTS FOR PROPAGATION PATHS INTERSECTING PLUME CENTERLINE. [A $=50 \mathrm{~cm} ; \mathrm{B}=200 \mathrm{~cm}$ ]. 

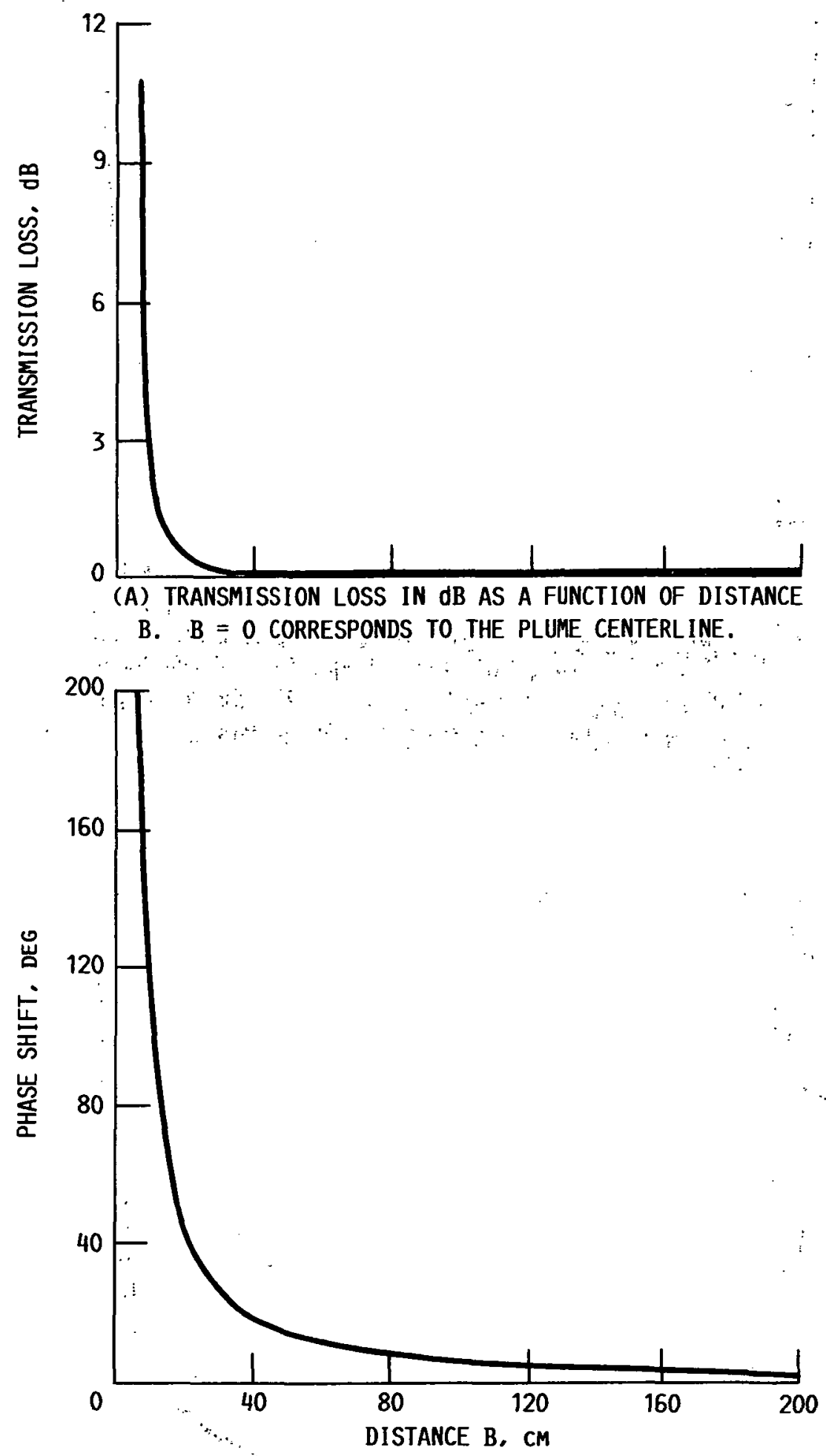

(B) PHASE SHIFT AS A.FUNCTION OF DISTANCE B.

FIGURE" 10 . - TRANSMISSION IMPACTS FOR. PROPAGATION PATHS PARALLEL TO PLUME CENTERLINE." $\left[A=50 \mathrm{~cm}: \varphi_{0}=0^{0}\right]$. 


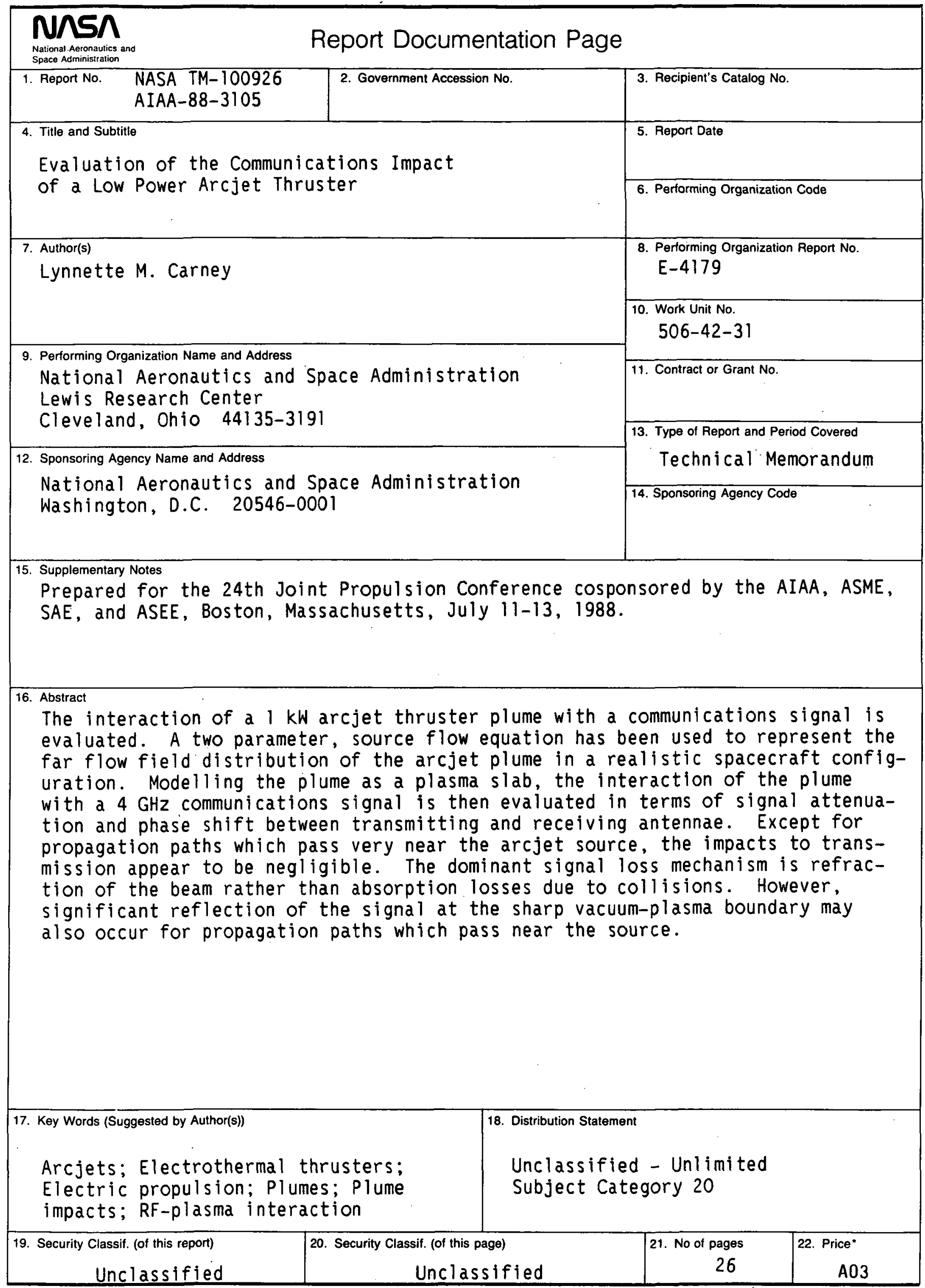


National Aeronautics and Space Administration

Lewis Research Center

Cleveland, Ohio 44135

Officlal Business

Penalty for Private Use $\mathbf{5 3 0 0}$

FOURTH CLASS MAIL

ADDRESS CORRECTION REQUESTED

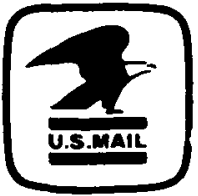

Postage and Fees Pard Nationat Aeronautics and

Space Administration

NASA 451 